\title{
Preface
}

\section{Romuald Szymkiewicz}

Gdańsk University of Technology, Faculty of Civil and Environmental Engineering, ul. G. Narutowicza 11/12, 80-233 Gdańsk, Poland, e-mail: romuald.szymkiewicz@ wilis.pg.gda.pl

By the courtesy of the Editor of Archives of Hydro-Engineering and Environmental Mechanics, the Department of Hydraulic Engineering has been invited to prepare the current issue of the journal devoted to the mathematical modeling of selected environmental problems. We highly appreciate this exceptional opportunity to give the journal's readers some insights into our current research.

The Department of Hydraulic Engineering, headed by Michał Szydłowski, D.Sc, Ph.D., Eng., belongs to the Faculty of Civil and Environmental Engineering of the Gdańsk University of Technology. Its scientific and research activities cover a wide range of subjects related to hydromechanics, hydraulics and hydrology. Recently, its main effort has focused on the two following fields:

- Investigation of water flow problems and pollutant transport in urban areas, i.e. run-off from urban catchments and unsteady flow in a storm sewer network;

- Physical and mathematical modeling of hydraulic and sanitary structures, including unsteady flow in pipe systems.

Since the aforementioned flow problems are described by a variety of mathematical formulations, their practical application requires a computer-based approach and numerical treatment. Thus, research on numerical methods constitutes an important part of the scientific activity of our department.

This issue of Archives of Hydro-Engineering and Environmental Mechanics contains a set of contributions closely related to the application of computer techniques in hydrology and hydraulics. They have been prepared by the research staff of the Department of Hydraulic Engineering as well as by our Ph.D. students.

We hope that the papers included in this issue will prove interesting for the readers and will make them more familiar with problems of mathematical modeling in water resources. 